\title{
Barriers to new drug development in respiratory disease
}

\author{
To the Editor:
}

The recent article by BARNES et al. [1] discussing barriers to new drug development in respiratory disease is particularly pertinent to the concerning situation for new tuberculosis (TB) drugs. In Médecins Sans Frontières (MSF)'s project in Karakalpakstan, Uzbekistan, 38\% of new patients present with multidrug-resistant (MDR)-TB [2]. The need for new TB drugs and regimens has never been greater, with treatment success rates of only $48 \%$ for MDR-TB patients and $<20 \%$ for extensively drug-resistant (XDR)-TB [3]. Despite two new compounds, bedaquiline and delamanid, being approved for the treatment of MDR-TB [4], the pipeline for new TB drugs is inadequate. Many compounds in phase II and IIl development are repurposed antibiotics, and may have pre-existing resistance (figure 1).

Bedaquiline and delamanid have not been studied together and are being added to the existing weak regimen with companion drugs that have limited efficacy data in TB [6]. The danger of this is already being seen with the first cases of bedaquiline resistance being reported [7]. What is needed are new compounds developed as part of new combinations to treat all forms of TB.

The added challenge with TB research and development (R\&D) is the lack of funding. Only $30 \%$ of the WHO's funding target for TB R\&D is being invested annually [8]. Between 2011 and 2013, the total investment by commercial developers in R\&D for new TB drugs declined, in part due to the withdrawal of large pharmaceutical companies from TB [8].

MSF, working with key stakeholders in TB drug development, has developed a proposal to address these gaps. The "Pull, Push, Pool" (3P) project aims to speed up development and ensure affordable access to new, effective and safe treatments for all forms of TB through a collaborative framework combining pull funding, push funding and a pooling mechanism for scientific knowledge and intellectual property (IP). Push, pull and pooling incentives have been used previously; for example, the UNITAID Medicines Patent Pool for HIV/AIDS medicines and the Xprize initiative (www.xprize.org/prizes). By combining these various incentives $3 \mathrm{P}$ aims to address the barriers in TB regimen development.

To fill the pipeline and encourage development of phase I TB compounds, milestone prizes (estimated range per prize of $\$ 40-70$ million) will be offered for TB compounds that enter early clinical development. To facilitate early regimen development, licenses will be negotiated for the TB indication of the new phase I compounds and pooling the IP will facilitate the development of a range of new TB compounds as regimens. To be eligible for a prize, data and IP must be pooled. Finally, research grants for regimen development will be provided throughout the $\mathrm{R} \& \mathrm{D}$ process, encouraging clinical trials on novel regimens rather than individual compounds. The successful regimens developed in this system will have been financed upfront through grants and prizes, so will be rapidly available for affordable generic production by qualified manufacturers.

The major risks of the $3 \mathrm{P}$ project are in the ambition that donors have for it. If the incentives are insufficient to ensure adequate numbers of compounds arrive at phase I and if insufficient funding for regimen development in subsequent phases is provided, the project will not succeed. However, the project

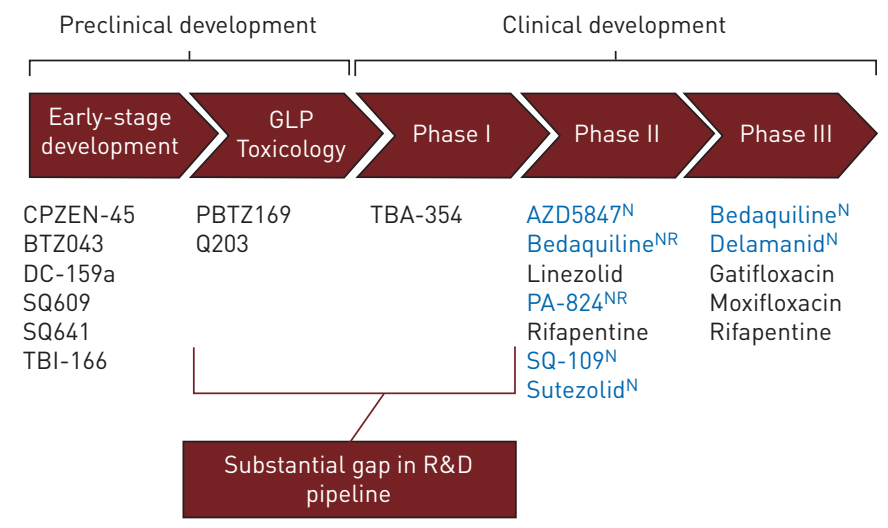

FIGURE 1 Tuberculosis drug pipeline. GLP: good laboratory practice; R\&D: research and development; N: new; NR: new regimen. Reproduced and modified from [5] with permission from the publisher. 
can start without the full allocation of funding in place and as prizes reward success, it allows more risk-averse funders, including governments, to fund elements of the proposal.

The needs of TB treatment, particularly MDR-TB, are great; the current system is under-resourced and not fit for purpose. New and innovative solutions [9] are required to ensure we are adequately prepared to meet the bold targets outlined in the WHO END TB strategy [10], and we hope the European Respiratory Society supports this initiative.

- @ERSpublications

Innovative solutions are required for TB R\&D to ensure the bold targets outlined in the WHO END TB strategy are met http://ow.ly/TLTmQ

Grania Brigden ${ }^{1}$, Philipp du Cros $^{2}$ and Sidney Wong ${ }^{3}$

${ }^{1}$ Médecins Sans Frontières, Geneva, Switzerland. ${ }^{2}$ Médecins Sans Frontières, London, UK. ${ }^{3}$ Médecins Sans Frontières, Operational Centre Amsterdam, Amsterdam, The Netherlands.

Correspondence: Grania Brigden, Médecins Sans Frontières, 78 Rue de Lausanne, Geneva 1211, Switzerland.

E-mail: graniabrigden@doctors.org.uk

Received: May 192015 | Accepted: July 022015

Conflict of interest: Disclosures can be found alongside the online version of this article at erj.ersjournals.com

\section{References}

1 Barnes P, Bonini S, Seeger W, et al. Barriers to new drug development in respiratory disease. Eur Respir J 2015; 45: $1197-1207$.

2 Nyang'wa BT, Brigden G, du Cros P, et al. Resistance to second-line drugs in multidrug-resistant tuberculosis. Lancet 2013; 381: 625 .

3 Migliori GB, Sotgiu G, Gandhi NR, et al. Drug resistance beyond XDR-TB: results from a large individual patient data meta-analysis. Eur Respir J 2013; 42: 169-79.

4 World Health Organization. Companion Handbook to the WHO Guidelines for the Programmatic Management of Drug-Resistant Tuberculosis. WHO, Geneva, 2015.

5 Stop TB Partnership Working Group on New Drugs. Drug Pipeline. www.newtbdrugs.org/pipeline.php.

6 Chang KC, Yew WW, Tam CM, et al. WHO group 5 drugs and difficult multidrug-resistant tuberculosis: a systematic review with cohort analysis and meta-analysis. Antimicrob Agents Chemother 2013; 57: 4097-104.

7 Somoskovi A, Bruderer V, Hömke $\mathrm{R}$, et al. A mutation associated with clofazimine and bedaquiline cross-resistance in MDR-TB following bedaquiline treatment. Eur Respir J 2015; 45: 554-557.

8 Frick M. 2014 Report on Tuberculosis Research Funding Trends, 2005-2013. New York, Treatment Action Group, 2015.

9 Migliori GB, Lienhardt C, Weyer K, et al. Ensuring rational introduction and responsible use of new TB tools: outcome of an ERS multisector consultation. Eur Respir J 2014; 44: 1412-1417.

10 World Health Organization. The END TB Strategy. www.who.int/tb/post2015_TBstrategy.pdf?ua=1 Date last updated: March 2015. 